\title{
$\mathrm{M}|\mathrm{R}| \mathrm{S}$
}

\section{Late-News Announcement Technology Update on Diamond Films April 24-25, 1989}

\section{Special Workshop to be Offered at the 1989 MRS Spring Meeting in San Diego, California}

\author{
Who should attend? Scientists, technologists, managers, and investors who need \\ up-to-the-minute facts on the status of this fast developing field...diamond \\ technology is projected to have a multi-billion dollar impact in the 1990 s... \\ International experts in diamond technology will speak on: \\ Novel methods of diamond film synthesis and characterization \\ Unique properties of diamond films \\ Technological applications of diamond films \\ Potential investment opportunities
}

\section{AMPLE TIME WILL BE RESERVED FOR DISCUSSION AND INTERACTION}

\section{Call for Papers}

Papers are being solicited in the four areas listed above. Abstracts can be submitted using the standard MRS template and format-instructions are in any 1988 or 1989 MRS Call for Papers. Abstracts can also be submitted on white bond paper, with the abstract typed in an area not exceeding $5 \mathrm{in} .(12.7 \mathrm{~cm})$ wide by $6 \mathrm{in} .(15.2 \mathrm{~cm})$ long. Submit abstracts by February 15, 1989 to one of the workshop organizers.

Prof. Akio Hiraki

Dept. of Electrical Engineering

Faculty of Engineering

Osaka University

Yamada-Oka Suita

Osaka 565, Japan

Telephone 81-6-877-5111 Ext. 4571

Fax 81-6-875-0506

Workshop Organizers

Dr. Dave Nelson

Chemistry Division

Office of Naval Research

800 North Quincy Street

Arlington, VA 2217-5000

Telephone (202) 696-4410
Prof. R.P.H. Chang

Dept. of Materials Science and Engineering

Tech Institute

Northwestern University

Evanston, IL 60208

Telephone (312) 491-3598

Fax (312) 491-4655 